\title{
Application of linear and non-linear P-sorption models for describing phosphate transport
}

\author{
S. E. A. T. M. VAN DER ZEE, F. LEUS \& M. J. P. F. LOUER
}

Department of Soil Science and Plant Nutrition, Wageningen Agricultural University, P.O. Box 8005, NL 6700 EC Wageningen

Received 22 May 1989; accepted 24 August 1989

\begin{abstract}
Phosphate transport in small columns was described using a two-site linear sorption model and using a non-linear adsorption-precipitation model. Using both approaches reasonable to good agreement with experimental breakthrough could be obtained. This result suggests the applicability of the simple linear model for engineering purposes, besides the more general applicability of the more involved non-linear model.
\end{abstract}

Keywords: phosphate, adsorption, precipitation, kinetics, transport, leaching

\section{Introduction}

The transport of phosphate $(P)$ ili soil is of interest from the scope of environmental concern due to the hazard of $\mathrm{P}$-leaching in areas receiving large quantities of animal manure or sewage effluent. To describe phosphate transport in small columns, van der Zee et al. (1989) developed a non-linear P-sorption/precipitation model in which adsorption was described with the Langmuir equation and with $\mathrm{P}$-precipitation given by a semi-empirical function of $I=\int\left(c-c_{e}\right) \mathrm{d} t$. Here $c$ is the concentration, $c_{e}$ the equilibrium concentration, and $t$ is time. Parameter assessment for this model was quite involved as adsorption and precipitation may occur simultaneously. Due to the non-linearity of the sorption model, no analytical solutions could be found to describe P-breakthrough, of use to directly fit experimental breakthrough curves. For the simpler two-site or dual porosity model (van Genuchten $\&$ Wierenga, 1976), with linear equilibrium adsorption in conjunction with a linear, first order kinetics sorption such a solution can be found. This allows parameter assessment directly from experimental breakthrough curves (Parker \& van Genuchten, 1984). Therefore we tested the applicability of both models for describing P-breakthrough. 


\section{Theory}

The applicability of the linear two-site model, with for site 1 and 2, respectively:

$$
\begin{aligned}
& Q_{1}=k_{1} c \\
& \mathrm{~d} Q_{2} / \mathrm{d} t=k_{\mathrm{r}}\left(k_{2} c-Q_{2}\right)
\end{aligned}
$$

( $Q$ is adsorbed amount, $k_{1}$ and $k_{2}$ are the adsorption constants, and $k_{\mathrm{r}}$ is the adsorption rate constant) may be tested with the mathematical formulation of the dual porosity model as these models are mathematically indistinguishable. In the latter model sorption and transport occur in a mobile soil region. First order mass transfer describes the diffusional transfer to solute from mobile to immobile parts of the soil where also sorption occurs. Sorption in both regions is an equilibrium process following a linear isotherm. Assuming near-equilibrium between the mobile and immobile zones, which appeared justified from preliminary fitting analyses, the breakthrough curves should be fitted with

$c_{\mathrm{r}}=\frac{c(L, t)-c_{i}}{c_{0}-c_{i}}=0.5 \operatorname{erfc}\left[\frac{R L-v t}{2(D R t)^{0.5}}\right]+0.5 \exp \left(\frac{v L}{D}\right) \operatorname{erfc}\left[\frac{R L+v t}{2(D R t)^{0.5}}\right]$

where $c_{\mathrm{r}}$ is the relative concentration, $c(L, t)$ is the effluent concentration, $L$ the column length, $c_{\mathrm{i}}$ the initial concentration, $c_{0}$ the feed concentration, $v$ the flow velocity, $D$ the dispersion coefficient and $R$ the retardation factor, and where erfc is the complementary error function.

\section{Materials and methods}

The used NKR-1 soil (20-40 cm depth) was derived from a field in grassland in coversand parent material and was described by van der Zee \& van Riemsdijk (1986). Analytical procedures to estimate sorption parameters were also given by van der Zee et al. (1989). Breakthrough curves were obtained for $\mathbf{P}\left(c_{\mathrm{o}}=3 \mathrm{~mol}\right.$ $\left.\mathrm{m}^{-3}\right)$ and chloride $\left(\mathrm{c}_{\mathrm{o}}=0.1 \mathrm{~mol} \mathrm{l}^{-1} \mathrm{NaCl}, \mathrm{c}_{\mathrm{i}}=0.01 \mathrm{~mol} \mathrm{l}^{-1} \mathrm{NaCl}\right)$ in columns with length $10 \mathrm{~cm}$ and with diameter $3.9 . \mathrm{cm}$. Curve-fitting of Equation 3 was done with the CXTFIT-code of Parker \& van Genuchten (1984), and yields estimates for $R$ and $D$.

\section{Results and discussion}

For the non-linear P-sorption model (van der Zee et al., 1989) the sorption parameters were obtained from independent sorption and desorption experiments.

Using the dispersivity found for chloride breakthrough (i.e $D / v=0.71 \mathrm{~cm}$ ), Pbreakthrough was calculated numerically for two columns. In Column 1 (Fig. 1) the flow velocity was held constant at $3.28 \mathrm{~cm} \mathrm{~h}^{-1}$ and in Column 2 (Fig. 2) it was in- 


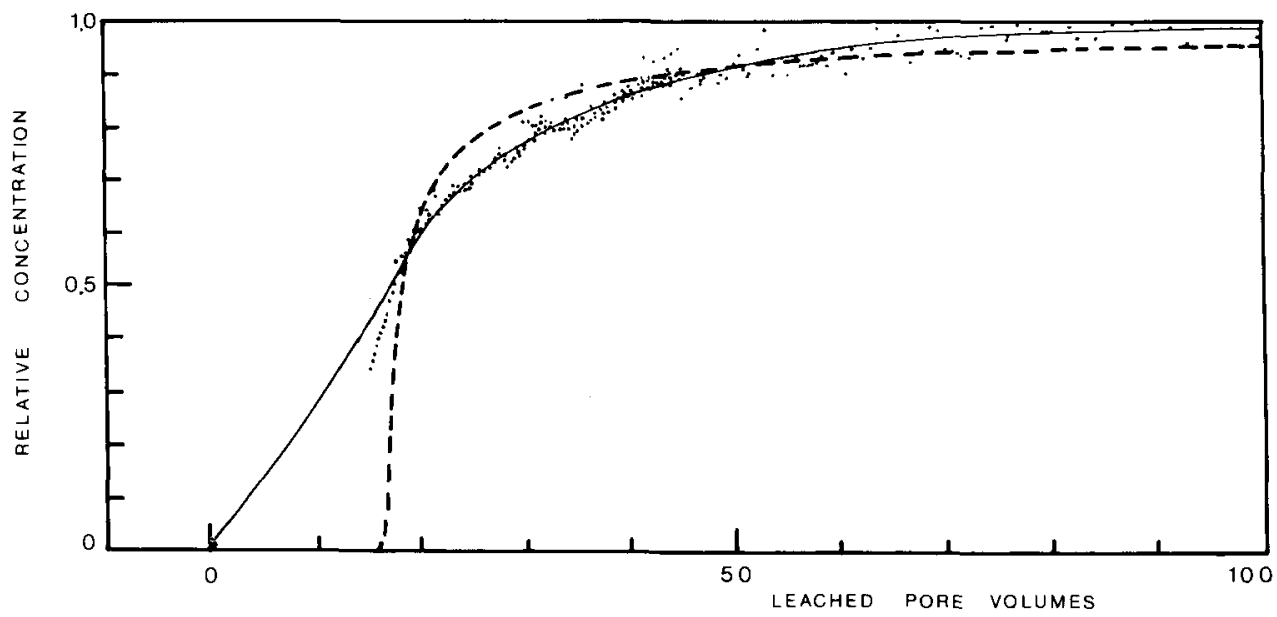

Fig. 1. Phosphate breakthrough for column 1. Experimental data $(\bullet)$, independent prediction with adsorption-precipitation model (dashed line), and fitted breakthrough curve with the two-site sorption model (solid line). Shown is the relative concentration, $c_{\mathrm{r}}$ (Equation 3 ) as a function of the percolated number of pore volumes $(=v t / L)$, both being dimensionless.

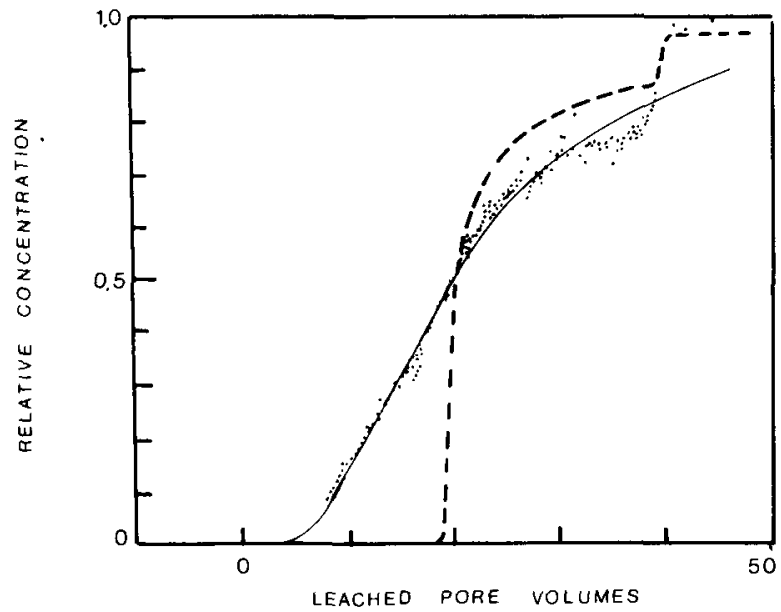

Fig. 2. Phosphate breakthrough for column 2. Experimental data $(\bullet)$, independent prediction with adsorption-precipitation model (dashed line), and fitted breakthrough curve with the two-site sorption model (solid line). Shown is the relative concentration, $c_{\mathrm{r}}$, (Equation 3) as a function of the percolated number of pore volumes $(=v t / L)$, both being dimensionless. The flow velocity $(v)$ was increased after 331 hours or about 40 percolated pore volumes, which was accounted for in the non-linear model calculations only.

creased after 331 hours from 1.20 to $5.65 \mathrm{~cm} \mathrm{~h}^{-1}$. Results are shown to agree reasonable with experimental data for Column 1 and for Column 2 only after initial breakthrough. 
Better agreement was obtained by fitting Equation 3 (two side model) to the data. This equation was fitted for Column 2 on the basis of results for time smaller than 331 hours. Retardation factors found for both columns were in good agreement $(R$ is 23 and 25), but apparent dispersion coefficients $(D)$ for $\mathrm{P}$ varied significantly (11 for Column 1 and 3 for Column 2).

These results suggest that if a system is considered that resembles the experimental one closely, the two-site sorption approach may be use for optimizing system variables. Such a situation may be relevant in e.g. wastewater purification systems. If, however, conditions (such as the feed concentration) may differ significantly from those of the experimental situation, prediction with the adsorption-precipitation model is preferred in view of the non-linearity of P-sorption over a wide range of $P$-concentrations, and its better mechanistic background.

\section{References}

Genuchten, M. Th. van \& P. J. Wierenga, Mass transfer studies in sorbing porous media: 1 Analytical solutions, Soil Science Society of America Journal 40: 473-480, 1976.

Parker, J. C. \& M. Th. van Genuchten, 1984. Determining transport parameters from laboratory and field tracer experiments. Bulletin 84-3, Virginia Agricultural Experimental Station, Blacksburg, 96 pp.

Zee, S. E. A. T. M. van der, F. Leus \& M. Louer, 1989, Prediction of phosphate transport in small columns with an approximate sorption kinetics model. Water Resources Research 25: 1353-1365.

Zee, S. E. A. T. M. van der \& W. H. van Riemsdijk, 1986, Sorption kinetics and transport of phosphate in sandy soil. Geoderma 38: 293-309.

This synopsis is based on a report entitled 'Vastlegging en transport van fosfaat in zandkolommen' by F. Leus, M. J. P. F. Louer \& S. E. A. T. M. van der Zee, Dept. of Soil Science \& Plant Nutrition, Wageningen Agricultural University, Wageningen, 1988, $80+63$ pp., 84 figs., 19 tables, 2 apps., 28 refs., in Dutch. Available as paper copy (order $R$ 100, $f 15$ including postage) at: NARD, c/o Pudoc, P.O. Box 4, 6700 AA Wageningen (telex 45015 bluwg nl). 